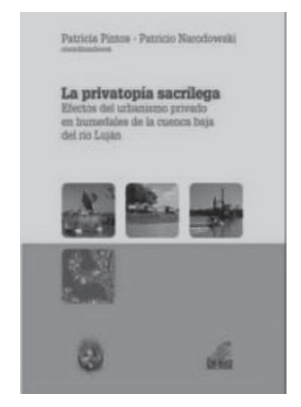

\title{
Patricia Pintos y Patricio Narodowski (coordinadores). \\ La privatopía sacrílega. Efectos del urbanismo privado en los humedales de la cuenca baja del río Luján
}

Buenos Aires: Ediciones Imago Mundi, 2012. 248 pp.

\author{
Voltaire Alvarado P. ${ }^{1}$
}

En el contexto de la liberalización sostenida del suelo, lo que le ha transformado en un sustrato de especulación de importante cuantía para distintos actores económicos y financieros, se enmarca la obra coordinada por Patricia Pintos y Patricio Narodowski, que define como área de estudio, a la cuenca del río Luján, en la provincia de Buenos Aires.

La compilación de estudios realizada por los coordinadores, y además autores, detalla las formas en que el perfeccionamiento hacia la liberalización del suelo, considerando el avance hacia regulación normativa que permite intervenir el espacio geográfico, produciendo tensiones entre el habitar que ofrece el actor inmobiliario frente a una unidad de paisaje natural, determinada por la excepcional condición de la cuenca del Luján, con resultado en el modelamiento artificial e intencionado del medio físico, hacia la constitución de la denominada privatopía sacrílega, como se denomina esta obra.

Esta denominación yace a los eventos descritos a lo largo de la obra, considerando problemáticas que no le están ajenas a la discusión actual frente a la transformación de los espacios rurales, hacia una urbanización utópica, en donde los servicios de la

\footnotetext{
1 Instituto de Geografía, Pontificia Universidad Católica de Chile (Chile).E-mail: vcalvarado@uc.cl
}

ciudad se trasladen al ámbito de lo agreste. Así, se analiza la condición de los servicios ambientales que la cuenca del Luján presta a los ecosistemas de la provincia y los impactos negativos hacia ellos, como resultado de este modelamiento. Asimismo, se aborda la dimensión de la vivienda exclusiva, el country o el condominio cerrado, desde donde se aprecia la tensión socioespacial sobre el territorio, el que se excluye hacia la tenencia exclusiva del entorno ideal.

También, en otra de las secciones, se revisan de forma crítica, la negatividad de las externalidades asociadas a este tipo de vivienda cerrada, ya sea hacia la protección y conservación de la flora y fauna presente en el área de estudio, considerando los factores que se aprecian en la legislación, las especies presentes, y la relación crítica que se establece entre ellas, y el emplazamiento de la vivienda cerrada, la comunidad vallada.

La idea de la privatopía sacrílega, se encierra en la persistencia en la instalación del neoliberalismo económico y político, que se hace visible en la materialidad espacial. Autores como David Harvey (2001), Neil Brenner (2004) o Saskia Sassen (1999) ya han abordado las consecuencias actuales que derivan de la instalación y perfeccionamiento del neoliberalismo. En el caso de la intervención del espacio en la lógica descrita, los coordinadores hacen una arqueología de la 
instalación neoliberal en Argentina, desde la llegada al poder del presidente Menem; y los caminos que esta instalación o readecuación del capitalismo de Estado en el país, ha recorrido hacia una intensa liberalización en el mercado de suelos y la vivienda.

La centralidad de esta privatopía sacrílega está en que el interés subjetivo del habitar en la condición utópica del espacio urbano, como el suburbio ideal o el campo teñido de ciudad, se analiza desde la fricción con el sistema físico-natural, anterior a la transformación de su sustrato por parte de los actores del mercado y la desregulación normativa. En este sentido, la privatopía se ve realizada a sí misma, cuando el anhelo de habitabilidad, por parte de los sectores acomodados de la sociedad argentina, se favorecen de la producción del espacio en la clave requerida: el country, la comunidad vallada, la ciudad exclusiva.

Lo sacrílego, por otra parte, aparece en la transformación de la naturaleza asociada a la cuenca del Luján. El espacio natural, defendido como la base prístina de toda cultura, se trastroca en su rol a partir de la visión del "progreso", visible a través de la vivienda exclusiva, sin considerar la irreversibilidad en la intervención de la naturaleza y la manipulación de sus tiempos, procesos y pausas. Esta acción, sacrílega en la voz de los coordinadores, es la que pretende desnudar al neoliberalismo urbano, como fuerza ilimitada, frente a la fragilidad de los ecosistemas y la débil, pero culposa, regulación.

Finalmente, los coordinadores entregan luces de la gobernanza de las masas críticas, que se alzan en situaciones como lo descrito a lo largo de la obra. Esta condición de organización y resistencia ante la vulnerabilidad de la comunidad local, desde las acciones emprendidas en Escobar, y la potencia de los proyectos, avizora cierta opción a los movimientos ciudadanos, considerando el peso que han asumido como reguladores externos de las formas del neoliberalismo urbano. La masa crítica, empoderada y consciente, se hace parte del debate en torno a la transformación de los espacios naturales y la calidad de vida, allá donde la comunidad aún sostiene los lazos de integración y solidaridad.

\section{Referencias bibliográficas}

HARVEY, D. Spaces of capital. Towards a critical geography. New York: Routledge, 2001.

SASSEN, S. La ciudad global: Nueva York, Londres, Tokio. Buenos Aires: Eudeba, 1999.

BRENNER, N. New state spaces: urban governance and the rescating of statehood. Oxford: Oxford University Press, 2004. 